\title{
Rhinoscleroma: a diagnosis not to be ignored
}

\author{
Nadia Baali', Sofia Berrada², Nadia Akhdari', Ouafa Hocar'1, Hanane Rais², Said Amal ${ }^{1}$
}

\author{
${ }^{1}$ Department of Dermatology, Mohammed VI CHU, Marrakech, Morocco, ${ }^{2}$ Department of Pathological Anatomy and \\ Cytology, CHU Mohamed VI, Marrakech, Morocco
}

Corresponding author: Dr. Nadia Baali, E-mail: nadia.baali@outlook.fr

\begin{abstract}
Rhinoscleroma is a chronic indolent granulomatous infection of the nose and the upper respiratory tract caused by Klebsiella rhinoscleromatis; this condition is endemic to many regions of the world including North Africa. We present a case of rhinoscleroma in a 47-year-old man with clinically diagnosed nodule in the nasal cavity. The histopathological examination revealed granulation tissue with plasma cells and Mikulicz's cells. The clinical and morphological picture of the case is a rare opportunity to recall a disease that is often overlooked by dermatologists.
\end{abstract}

Key words: Rhinoscleroma; Morocco; Klebsiella rhinoscleromatis

\section{INTRODUCTION}

Rhinoscleroma is a chronic and specific granulomatous disease caused by enterobacteria of the family Klebsiella (Klebsiella rhinoscleromatis) with a tropism for the upper airways. The purpose of our work is to describe, through an observation, the epidemiological-clinical profile of this pathology and to demonstrate its peculiarities of management.

\section{CASE REPORT}

Patientaged 47, living in very poor hygienic condition, agriculture by professio, having as antecedent smoking and chronic alcoholism.He was admitted to our formation for a unilateral nasal obstruction, progressive installation, associated with persistent rhinitis evolving since 04 years. Clinical examination revealed a crusted nodular lesion of the right wing of the nose, which had been evolving for 4 years, increasing very gradually in volume (Fig. 1).

The rhino-nasofibroscopy visualized an almost complete obstruction by an ulcerated tumor of the right nasal fossa, with a septal deviation. The oral cavity, pharynx and larynx were normal. HIV, TPHA/VDRL serologies were negative. The diagnosis of rhinoscleroma was confirmed by the presence of MIKULICZ cells in the pathological study (Figs. 2 and 3).

The first control evolution at 3 weeks was marked by a slight improvement but with persistence of the nasal obstruction, additional surgery was necessary in this case and the patient was referred to the department of otorhinolaryngological surgery.

\section{DISCUSSION}

The literature review shows that rhinoscleroma is particularly prevalent in tropical Africa, the Maghreb, Latin America, southern Asia and central Europe [1]. The pathogenesis of the affection is not yet well understood. Genetic predisposition and/or immunodeficiency have been advanced by some authors $[2,3]$.

The diagnosis of rhinoscleroma can be made at the catarrhal stage, by identification of K. rhinoscleromatis on nasal smear culture on specific media. However, most cases are diagnosed, as in our patient, at the granulomatous stage. The germ can be isolated at this stage on the granulated tissue crushers. The histological study of the biopsy pieces makes it possible to highlight the Mikulicz cells, considered as characteristic of the affection [4].These are foamy histiocytes with a single and uniform nucleus, small,

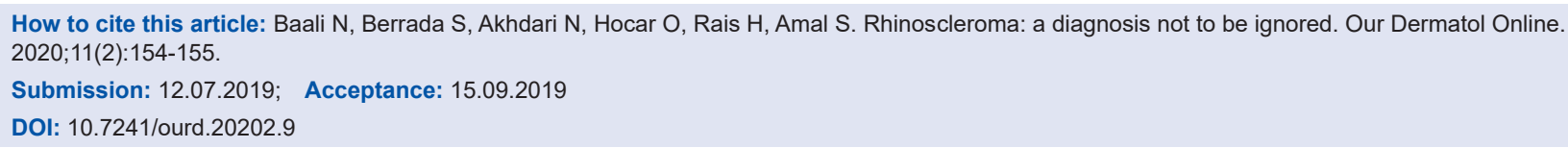




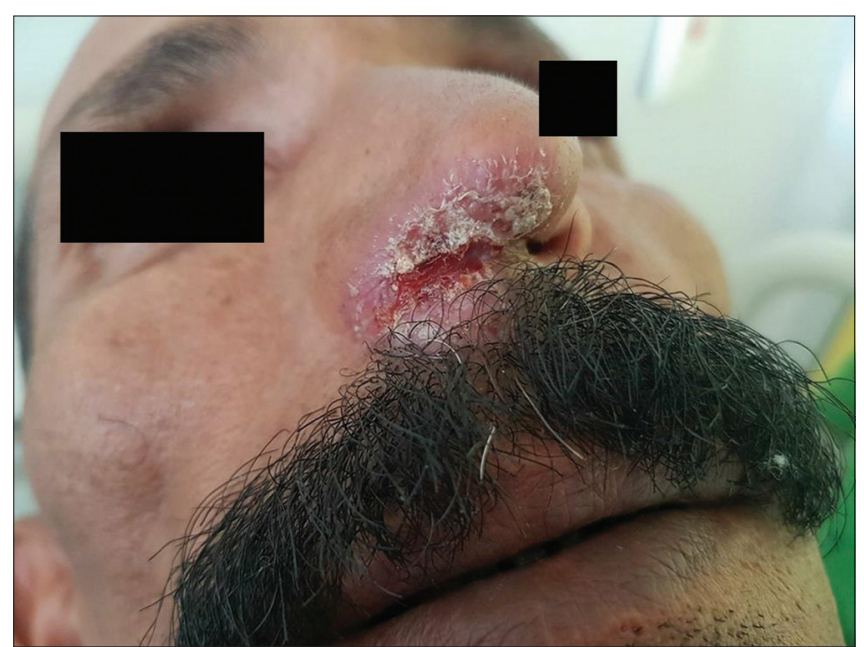

Figure 1: Erythematous and ulcerous lesion of the right wing of the nose.

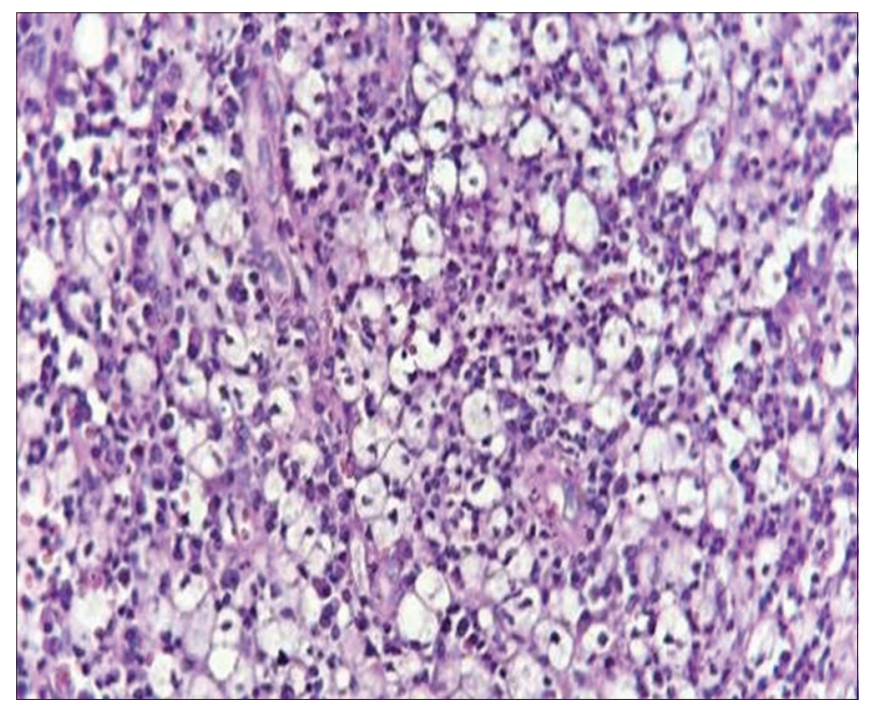

Figure 2: Large foam cells with vacuolar cytoplasm: Mikulicz cells (H\&E, x20).

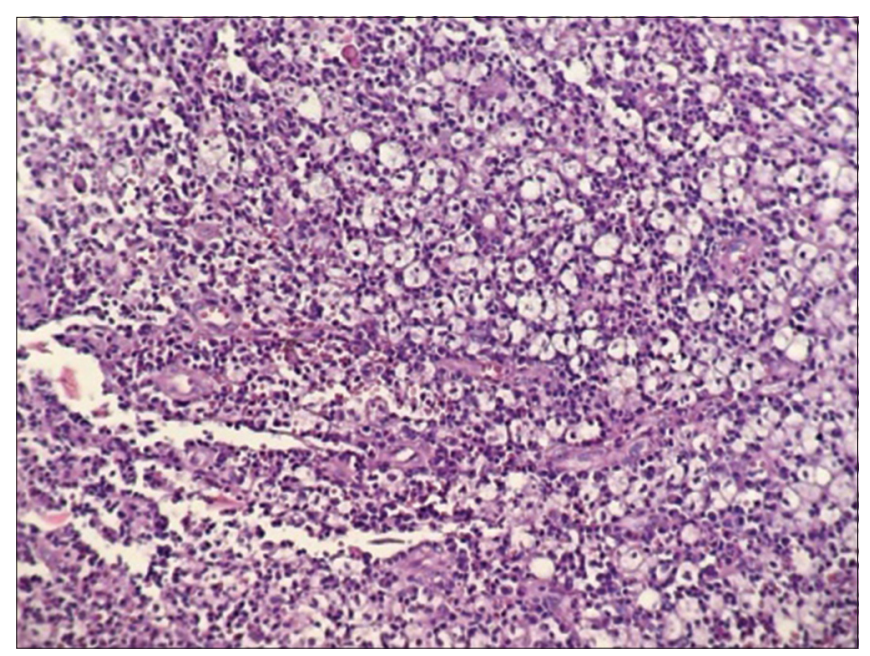

Figure 3: Cellules de Mikuliczs renfermant quelques microorganismes en forme de bâtonnet (H\&E, x40). round, hyperchromatic and eccentric. However, histiocytes of similar morphology can be observed in leprosy. Indeed, Virchow cells characteristic of lepromatous leprosy can resemble Mikulicz cells. The differential diagnosis may be with leprosy, syphilis, tuberculosis, Wegener's disease, mucocutaneous leishmaniasis, rhinosporidiosis, hence the importance of correlating the histological results with the clinic [5]. The treatment is primarily medical to eradicate the germ of the outbreak, stabilize or partially reduce the lesions and avoid functional or aesthetic complications. It was based on streptomycin, rifampicin, sulfonamides and clofazimine [6]. The efficacy of fluoroquinolones has been demonstrated in our management.However, surgery in addition to medical treatment seems to be necessary especially in this case [7].

\section{CONCLUSION}

Finally, rhinoscleroma is very rare in dermatology, contrary to otorhinolaryngological surgery. The dermatologist should seek systematically in front of any centro-facial granuloma to avoid mutilating scars.

\section{Consent}

The examination of the patient was conducted according to the Declaration of Helsinki principles.

\section{REFERENCES}

1. N'gattiaaKV, KacouchiaaN, Koffi-N'guessanbL, Mobio NM. KouassiNdjeundoJ, Kouassi M, et al. Étude rétrospective du rhinosclérome. À propos de 14 cas dans les services d'ORL des CHU de Côte d'Ivoire. Ann Français OtorhinolaryngolPatholCervicofacial. 2011;128:8-11.

2. Allah KC, Kossoko H, Assi DjéBiDjé V, Yéo S, Richard M. KadioRhinosclérome géant. RevStomatol Chir Maxillofac Chir Oral. 2013;114:184-6.

3. De Pontual L, Ovetchkine P, Rodriguez D, Grant A, Puel A, Bustamante J, Plancoulaine S, et al. Rhinoscleroma: a French national retrospective study of epidemiological and clinical features. Clin Infect Dis. 2008;47:1396-402.

4. Gaafar HA, Gaafar AH, Nour YA. Rhinoscleroma: an updated experience through the last 10 years. Acta Oto Laryngol. 2011;131:440-6.

5. Mukara BK, Munyarugamba P, Dazert S, Löhler JRhinoscleroma: a case series report and review of the literature.Eur Arch Otorhinolaryngol. 2014;271:1851-6.

6. -Faso Elola A, Gyebre YMC, Ouattara M, Ouoba K.Le rhinosclérome: deux observations à Bobo-Dioulasso au Burkina Faso. Méd Santé Trop. 2012;22:409-11.

7. Ibrahim D, Fayed A. Report of a case of giant rhinoscleroma: CT and MRI. BJR Case Rep. 2018;4:20180027.

Copyright by Nadia Baali, et al. This is an open-access article distributed under the terms of the Creative Commons Attribution License, which permits unrestricted use, distribution, and reproduction in any medium, provided the original author and source are credited.

Source of Support: Nil, Conflict of Interest: None declared. 